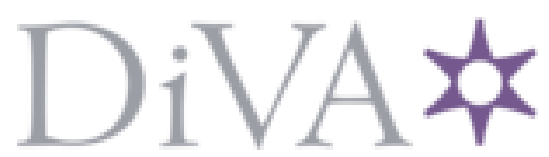

http://www.diva-portal.org

This is the published version of a paper published in LASE Journal of Sport Science.

Citation for the original published paper (version of record):

Nilsson, J., Cardinale, D. (2015)

Running economy and blood lactate accumulation in elite football players with high and low maximal aerobic power.

LASE Journal of Sport Science, 6(2): 44-51

Access to the published version may require subscription.

N.B. When citing this work, cite the original published paper.

You are free to: Share - copy and redistribute the material in any medium or format. The licensor cannot revoke these freedoms as long as you follow the license terms. You must give appropriate credit, provide a link to the license, andindicate if changes were made. You may do so in any reasonable manner, but not in any way that suggests the licensor endorses you or your use. You may not use the material for commercial purposes. If you remix, transform, or build upon the material, you may not distribute the modified material. You may not apply legal terms or technological measures that legally restrict others from doing anything the license permits. Full-text available free of charge at http:// journal.lspa.lv/

Permanent link to this version:

http://urn.kb.se/resolve?urn=urn:nbn:se:gih:diva-4291 


\title{
RUNNING ECONOMY AND BLOOD LACTATE ACCUMULATION IN ELITE FOOTBALL PLAYERS WITH HIGH AND LOW MAXIMAL AEROBIC POWER
}

\author{
Johnny Nilsson ${ }^{1,2}$, Daniele Cardinale ${ }^{2,3}$ \\ ${ }^{1}$ University of Dalarna, Falun, Sweden \\ ${ }^{2}$ The Swedish School of Sport and Health Sciences, Stockholm Sweden \\ ${ }^{3}$ Swedish Sports Confederation, Stockholm, Sweden \\ Address: 79188 Falun, University of Dalarna, Sweden \\ Phone: + 4623778000 \\ E-mail: jns@du.se
}

\begin{abstract}
The purpose was to determine running economy and lactate threshold among a selection of male elite football players with high and low aerobic power. Forty male elite football players from the highest Swedish division ("Allsvenskan") participated in the study. In a test of running economy (RE) and blood lactate accumulation the participants ran four minutes each at 10, 12, 14, and $16 \mathrm{~km} \cdot \mathrm{h}^{-1}$ at horizontal level with one minute rest in between each four minutes interval. After the last sub-maximal speed level the participants got two minutes of rest before test of maximal oxygen uptake $\left(V O_{2 m a x}\right)$. Players that had a maximal oxygen uptake lower than the average for the total population of $57.0 \mathrm{~mL} \mathrm{O}_{2} \bullet \mathrm{kg}^{-1} \bullet$ minute $^{-1}$ were assigned to the low aerobic power group (LAP) $(n=17)$. The players that had a $V O_{2 \max }$ equal to or higher than $57.0 \mathrm{~mL} \mathrm{O}_{2} \bullet \mathrm{kg}^{-1} \bullet$ minute-1 were selected for the high aerobic power group $(H A P)(n=23)$. The $V_{2} O_{2 x}$ was significantly different between the HAP and LAP group. The average RE, measured as oxygen uptake at 12, 14 and $16 \mathrm{~km} \bullet h^{-1}$ was significantly lower but the blood lactate concentration was significantly higher at 14 and $16 \mathrm{~km} \cdot h^{-1}$ for the LAP group compared with the HAP group.
\end{abstract}

Key words: football, aerobic power, running economy, lactate accumulation

\section{Introduction}

The duration of the football match in combination with the load on the aerobic system of about $75 \%$ of maximal oxygen uptake $\left(\mathrm{VO}_{2 \max }\right)$ 
(Stølen et al. 2005), indicate that the main energy contribution comes from aerobic processes. The size of the mean aerobic power of a team is related to the position in the league (Apor et al., 1988, Wisslöff et al., 1998). Thus, aerobic power, per se, seems to be a performance factor in football. From a theoretical point of view running economy (RE), measured as oxygen uptake per $\mathrm{kg}$ body mass at a given speed and lactate threshold (LT), defined as the work intensity at which the lactate no longer can be metabolized at a rate as it is produced, may also be performance factors in football.

In aerobic sports where the speed is kept constant or close to constant for a long period of time the benefits with a good running economy and a high lactate threshold are obvious and have proven to be important for a high performance level (Sjödin \& Svedenhag, 1985). However, the football game is also characterized by a constantly occurring variation in work intensity related to what happens on the football field like e.g. standing, walking, jogging, running, high-speed running, and sprinting. High speed running and sprinting will highly tax the anaerobic energy system involved in the energy production causing an oxygen deficit which will be paid for during the periods of low work intensity. This transition between energy systems in combination with different locomotory forms may make assumptions about the specific contribution from a good RE and high LT harder to do (Buchheit et al., 2011). However, it has been argued that football players with a high $\mathrm{VO}_{2 \max }$ have a lower lactate production at given speeds (MacRae et al., 1992). If this also is the case with RE still lacks scientific support. Although, test data only indirectly indicate the association between $\mathrm{RE}$, LT and $\mathrm{VO}_{2 \max }$ versus performance during the game it may give some insight into how these parameters are interrelated.

Thus, the purpose with the present investigation was to study maximal oxygen uptake, running economy and blood lactate accumulation at given speeds in elite male football players with high and low maximal aerobic power. The comprehensive set of data will allow that the interrelation between these parameters can be simultaneously evaluated.

\section{Materials and methods}

In total 40 male elite football players at the highest Swedish division ("Allsvenskan") took part in the study at the end of the match season. The players were informed about the tests and their right to finish without giving any explanation. The players were divided into two groups, a high aerobic power group (HAP) and a low aerobic power group (LAP) with respect to their $\mathrm{VO}_{2 \max }$ with the mean value of the whole group of $57.0 \mathrm{~mL} \mathrm{O}{ }_{2} \bullet \mathrm{kg}^{-1} \bullet$ minute $^{-1}$ as reference value (Tab. 1). 
Average $( \pm \mathrm{sd})$ age, height, body mass and $\mathrm{VO}_{2 \max }$ of players in the high and low aerobic power groups

\begin{tabular}{|l|c|c|c|c|}
\hline & Age (years) & Height (m) & Body mass $(\mathrm{kg})$ & $\begin{array}{l}\mathrm{VO}_{2 \max } \\
\left(\mathrm{mL} 02 \cdot \mathrm{kg}^{-1} \cdot \mathrm{min}^{-1}\right)\end{array}$ \\
\hline $\begin{array}{l}\text { High aerobic } \\
\text { power group } \\
(\mathrm{N}=23)\end{array}$ & $22.5 \pm 3.3$ & $1.80 \pm 0.05$ & $76.3 \pm 5.3$ & $59.7 \pm 2.3$ \\
\hline $\begin{array}{l}\text { Low aerobic } \\
\text { power group } \\
(\mathrm{N}=17)\end{array}$ & $26.8 \pm 4.8$ & $1.81 \pm 0.07$ & $82.8 \pm 8.5$ & $53.2 \pm 2.0$ \\
\hline
\end{tabular}

Apparatus and test setup

Running economy, blood lactate accumulation and maximum oxygen uptake was determined during running on a motor-driven treadmill (Cybex Stable flex, Cybex International Inc., US). RE was defined as oxygen uptake $\left(\mathrm{mL} \mathrm{O}_{2} \bullet \mathrm{kg}^{-1} \cdot\right.$ minute $\left.{ }^{-1}\right)$ during running at a given speed. Blood lactate accumulation at given speeds was used to define lactate threshold (Heck et al., 1985).

In order to allow comparison of RE and LT in the present study with future studies measures were undertaken to calibrate speed and to define the stiffness characteristics of the treadmill. The treadmill speed was calibrated by recording a reference point on the moving treadmill belt by means of a video camera (film rate: $50 \mathrm{~Hz}$ ). The preset speed and the calculated speed from the video recording were compared when the treadmill was loaded with a subject $\left(71.3 \mathrm{~kg}\right.$ body mass) running on the treadmill from $10 \mathrm{~km} \cdot \mathrm{h}^{-1}$ to $20 \mathrm{~km} \cdot \mathrm{h}^{-1}$. The deviation from the preset speed was less than $1.5 \%$ in all cases. The stiffness of the running surface of the treadmill, defined as surface deflection per kilo load (per $\mathrm{N}$ vertical force), was tested. The treadmill belt was cumulatively loaded with weights $(50 \mathrm{~kg})$ up to $250 \mathrm{~kg}$, which corresponds to a vertical force of $2453 \mathrm{~N}$. The deflection of the treadmill was measured with a micrometer at the level of the load position. Surface deflection for every added $50 \mathrm{~kg}$ weight was registered. The relationship between deflection $(\mathrm{Y})$ per added mass $(\mathrm{X})$ was best expressed by the polynomial equation $\mathrm{Y}=0.025876+0.04065 \mathrm{X}+\left(-1.48756 \mathrm{E}^{-5} \mathrm{X}^{2}\right)$.

The oxygen uptake at sub-maximal and maximal workload during running on a treadmill was determined by means of an automatic measuring system for oxygen uptake with a mixing chamber (OxygenPro, Jaeger $\mathrm{GmbH}$, Germany). This system was validated before the test by means of a comparative in series measurements of OxyconPro and Douglas bags that 
were analyzed separately. The OxyconPro was also validated by means of a metabolic simulator (oxygen uptake simulator) (Vacu-Med Inc. US). No significant deviation in results was seen when the results from these comparisons were analyzed. The blood lactate concentrations during running on sub-maximal and maximal intensities were determined by blood from a punctured fingertip. The blood sample $(20 \mu \mathrm{L})$ was analyzed with an electro-enzymatic method (Biosen C-line, EKFdiagnostic $\mathrm{GmbH}$, Germany), which was calibrated by means of standard lactate solutions at a concentration of 2.7 and $18 \mathrm{mM} \cdot \mathrm{L}^{-1}$.

Test procedures

All participating players were accustomed to treadmill running before the test. In the running economy and lactate threshold test the participants ran four minutes each at $10,12,14$, and $16 \mathrm{~km} \cdot \mathrm{h}^{-1}$ on the treadmill at horizontal level. Between the run at each speed level the participants got one minute of rest when a blood sample was collected. After the last submaximal speed level the participants got two minutes of rest before the test of $\mathrm{VO}_{2 \text { max }}$. This test of $\mathrm{VO}_{2 \max }$ started with running on the horizontal level at $14 \mathrm{~km} \bullet \mathrm{h}^{-1}$. After one minute the speed was increased to $15 \mathrm{~km} \bullet \mathrm{h}^{-1}$ and this speed were kept for one minute. Subsequently the speed was increased with $0.5 \mathrm{~km} \cdot \mathrm{h}^{-1}$ each minute until the speed $20 \mathrm{~km} \bullet \mathrm{h}^{-1}$ was reached. Most of the players were physically exhausted and had terminated the test before this speed level. The different test parameters were constantly checked during the test of $\mathrm{VO}_{2 \max }$. Criteria for reaching $\mathrm{VO}_{2 \max }$ were: "leveling off" in oxygen uptake and/or respiratory exchange ratio (RER) $>1.1$, perceived exertion according to Borg and co-workers (1985) higher than or equal to "very hard" and rate of increase in pulmonary ventilation. The rated perceived exertion was registered immediately after the termination of the test of maximal oxygen uptake and after three minutes a blood sample was collected for determination of blood lactate concentration.

Statistics

For statistical calculations the StatView statistical package for (Windows version 5.0, SAS Institute Inc., USA) was used. All data are reported as mean \pm standard deviation (sd). Differences between the LAP and HAP group were assessed by means of a t-test. Statistical significance was set at the alpha level 0.05 .

\section{Results}

Statistical comparisons were performed between the two groups. The players in the HAP group was significantly younger, had a significantly lower body mass than the LAP group (Tab. 1). Significant differences 
were found in $\mathrm{VO}_{2 \max }$, running economy at $12,14,16 \mathrm{~km} \bullet \mathrm{h}^{-1}$ (Figure 1), as well as in lactate accumulation at 14 and $16 \mathrm{~km}^{\bullet} \mathrm{h}^{-1}$ (Figure 2).

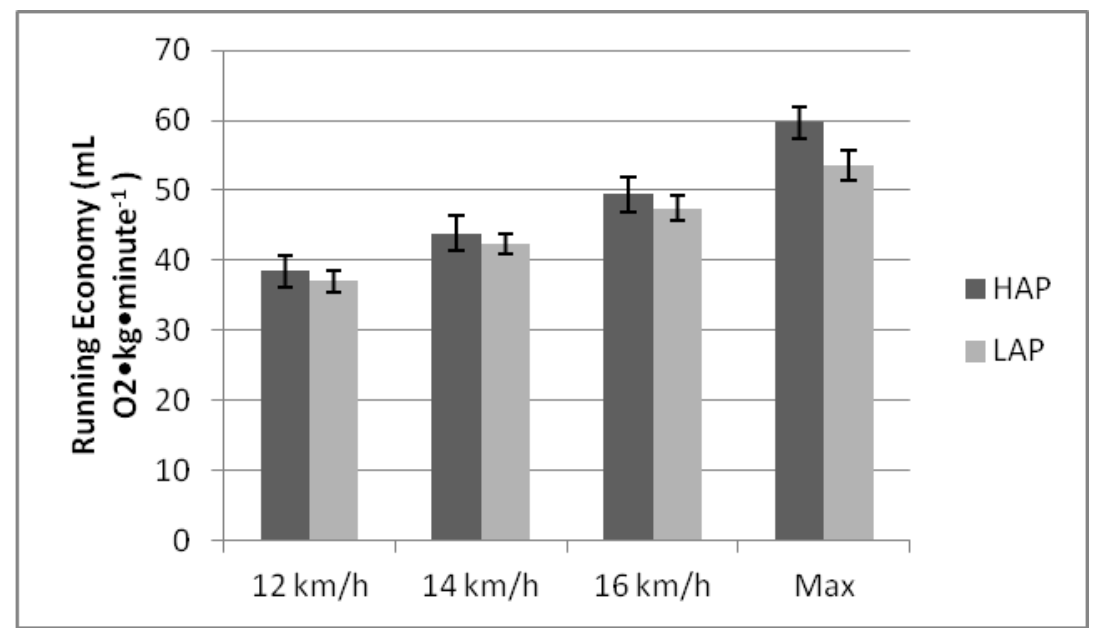

Figure 1. Mean $( \pm \mathrm{sd})$ oxygen uptake during running at 12,14 and $16 \mathrm{~km} \bullet \mathrm{h}^{-1}$ as well as maximal oxygen uptake for the high aerobic power group (HAP) and low aerobic power group (LAP)

The HAP group showed $3.5-4.1 \%$ significantly higher oxygen uptake at speed 12,14 , and $16 \mathrm{~km} \cdot \mathrm{h}^{-1}$ than the LAP group (Figure 1). On the other hand, the blood lactate accumulation was significantly higher for LAP compared to HAP at 14 and $16 \mathrm{~km} \bullet \mathrm{h}^{-1}$ (Figure 2).

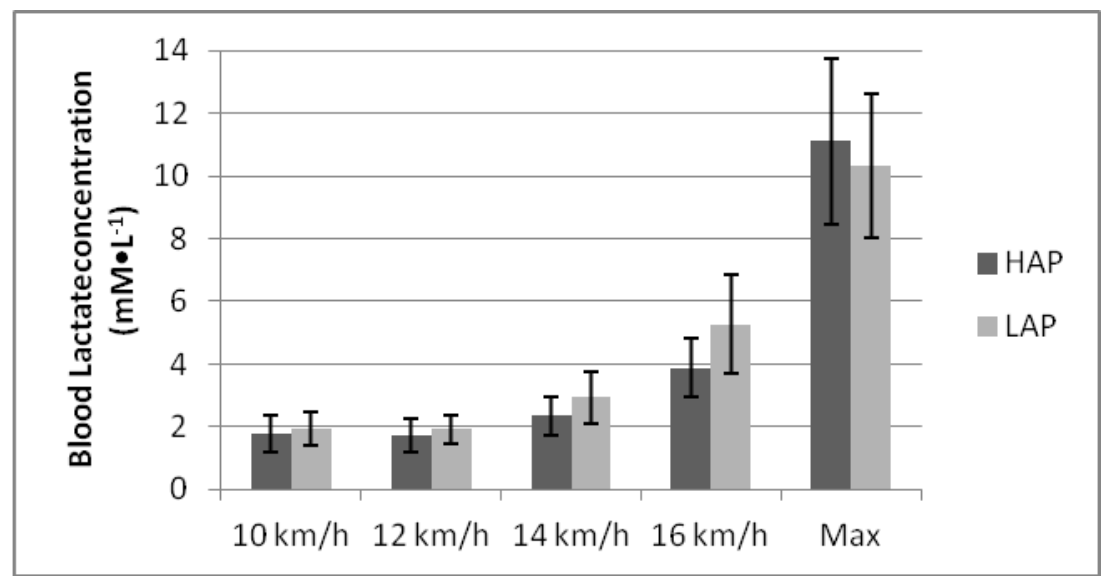

Figure 2. Mean ( \pm sd) blood lactate accumulation during running at 12, 14 and $16 \mathrm{~km} \cdot \mathrm{h}^{-1}$ as well as after test of maximal oxygen uptake for the high aerobic power group (HAP) and low aerobic power group (LAP) 


\section{Discussion}

Successful performance in endurance events are strongly correlated to $\mathrm{VO}_{2 \max }$ (Bangsbo, 1994; Ekblom, 1986; Mohr et al., 2003; Withers et al., 1982). Football can be regarded as a complex endurance sport in which it also has been shown that $\mathrm{VO}_{2 \max }$ can be related to team success (Apor et al., 1988; Wislöff et al.,1998). Fatigue-related decline in technical proficiency for a given intensity is associated with the fitness level of the players (Rampinini et al., 2008). There was a significant difference in $\mathrm{VO}_{2 \max }$ between the LAP group and the HAP group. In endurance sport athletes with similar $\mathrm{VO}_{2 \max }$ running economy is a better performance predictor than $\mathrm{VO}_{2 \max }$ alone (Withers et al., 1982; Knowles \& Brooks, 1974). Running economy among endurance runners seems to be related to morphological factors where a high percentage of slow twitch fibers is associated with a superior running economy (MacRae et al., 1992; Heller et al., 1992; Hoff \& Helgerud, 2002). It has also been shown that long distance runners have a better running economy than middle-distance runners (Rienzi et al., 2000; Saltin, 1973; Bunc et al., 1987). The demands in football will probably complicate this optimization due to the need for explosive movements and sprints as well as aerobic performance in combination. The running economy was significantly better i.e. less oxygen was used in the LAP group at the higher sub-maximal speeds $\left(12,14\right.$ and $\left.16 \mathrm{~km}^{\bullet} \mathrm{h}^{-1}\right)$. Thus, in our study the HAP group utilized significantly more oxygen than the LAP group at the tested speeds. The lower blood lactate production in the HAP group was in line with the results of MacRae and co-workers (1992). From a performance perspective it is however important to note that the HAP group could run at 14 and $16 \mathrm{~km} \cdot \mathrm{h}^{-1}$ with a significantly lower blood lactate concentration, which may indicate that the players in the HAP group consumed more oxygen at a given speed but with a lower lactate production. In endurance events the ability to maintain a high speed with a low blood lactate concentration is important. Thus, a small blood lactate accumulation at given speeds is a good indicator of endurance performance (Bangsbo et al., 1991). According to Ziogas and co-workers (2011) velocity at anaerobic threshold can be used to better discriminate endurance characteristics of football teams of different level along with maximum oxygen uptake during preseason testing.

\section{Conclusions}

The players in the HAP group i.e. players with the highest maximal oxygen uptake showed higher oxygen uptake at higher speeds but lower lactate concentration than the LAP group. Thus, the HAP group may have spent more oxygen to avoid excessive lactate production something that 
may be beneficial to avoid fatigue. At the moment the data are only indirect and further studies are needed to understand the role of RE and blood lactate accumulation in football.

\section{References}

1. Apor, P. (1988). Science and football. London E\&FN Spon, 95-107.

2. Bangsbo, J., Nörregaard, L., \& Thorsöe, F. (1991) Activity profile of competition soccer. Can J Sports Sci, Jun; 16 (2): 110-116.

3. Bangsbo, J. (1994). The physiology of soccer: with special reference to intense intermittent exercise. Acta Physiol Scand, 15, Suppl. 619: 1-156.

4. Borg, G., Ljunggren, G., \& Ceci, R. (1985). The increase of perceived exertion, aches and pain in the legs, heart rate and blood lactate during exercise on a bicycle ergometer. European Journal Applied Physiology, 54, 343-349.

5. Buchheit, M., Haydar, B., Hader, K., Ufland, P., \& Ahmaidi, S. (2011). Assessing running economy during field running with changes of direction: application to $20 \mathrm{~m}$ shuttle runs. International Journal of Physiology and Performance, 6, 380-395.

6. Bunc, V., Heller, J., Leso, J. et al. (1987). Ventilatory threshold in various groups of highly trained athletes. Int J Sports Med; 8: 275-280.

7. Ekblom, B. (1986). Applied physiology of soccer. Sports Med, Jan-Feb; 3 (1): 50-60.

8. Heck, H., Mader, A., Hess, G., Mucke, S., Muller, R., \& Hollman, W. (1985). Justification of the $4 \mathrm{mmol} /$ liter lactate threshold. Int J Sports Med, 6: 117.

9. Heller, J., Prochazka, L., Bunc, V. et al. (1992). Functional capacity in top league football players during the competitive season. J Sports Sci, 10: 150.

10. Hoff, J., \& Helgerud, J. (2002). Maximal strength training enhances running economy and aerobic endurance performance, In: Hoff. J., Helgerud, J., editors, Football (soccer). Trondheim: Norwegian University of Science and Technology.

11. Hoff J., A. B. (1995). The effects of maximum strength training on throwing velocity and muscle strength in female team-handball players. J Strength Cond Res, 9 (4): 255-258.

12. Knowles, J.E., \& Brooks, J.D. (1974). A movement analyses of players behaviour in soccer match performance. Paper presented at the $8^{\text {th }}$ conference. Salford: British Society of Sports Psychology.

13. MacRae, H.S.-H., Dennis, S.C., Bosch, A.N., et al. (1992). Effects of training in lactate production and removal during progressive exercise in human. J Appl Physiol, May; 72 (5): 1649-56.

14. Mohr, M., Krustrup, P., \& Bangsbo, J. (2003) Match perfomlance of highstandard soccer players with special reference to development of fatigue. $J$ Sports Sci Jul; 21 (7): 519-528. 
15. Rampinini, E., Impellizzeri, FM., Castagna, C., Azzalin, A., Ferrari Bravo, D., \& Wisløff, U. (2008). Effect of match-related fatigue on short-passing ability in young soccer players. Med Sci Sports Exerc., 40: 934-942.

16. Reilly, T., \& Bowen, T. (1984). Exertional costs of unorthodox modes of motion. Perceptual and motor skills, pp. 58; 49-50.

17. Rienzi, E., Drust, B., Reilly, T., et al. (2000). Investigation of anthropometric and work-rate profiles of elite South American international soccer players. J Sports Med Phys Fitness, Jun; 40 (2):162-169.

18. Saltin, B. (1973). Metabolic fundamentals in exercise. Med Sci Sports Exerc, 5. 137-146.

19. Sjödin B., \& Svedenhag J. (1985). J. Applied physiology of marathon running. Sports Med, 2: 83-89.

20. Stølen, T., Chamari, K., Castagna, C., \& Wisløff, U. (2005). Physiology of soccer: an update. Sports Med, 35: 501-536.

21. Wisløff, U. (2004). Strong correlation of maximal squat strength with sprint performance and vertical jump height in elite soccer players. $\mathrm{Br} J$ Sports Med, 38:285-288.

22. Wislöff, U., Helgerud J., \& Hoff J. (1998). Strength and endurance of elite soccer players. Med Sci Sports Exerc, 30 (3): $462-467$.

23. Withers, R.T., Maricic, Z., Wasilewski, S., et al. (1982). Match analysis of Australian professional soccer players. J Hum Mov Stud, 8: 159-176.

24. Ziogas, G.G., Patras, K.N., Stergiou, N., \& Georgoulis, A. D. (2011) Velocity at lactate threshold and running economy must also be considered along with maximal oxygen uptake when testing elite soccer players during preseason. Journal of Strength and Conditioning Research, 25(2): 414-419.

Submitted: October 24, 2015 Accepted: December 15, 2015 